\title{
Enraizamento de estacas de castanha-de-cutia com uso de ácido indolbutírico
}

\author{
Raimundo Cajueiro LEANDROํ, Kaoru YUYAMA² \\ RESUMO \\ A castanha-de-cutia (Couepia edulis Prance) é uma oleaginosa nativa da Amazônia encontrada na terra firme, com maior \\ frequiência no Estado do Amazonas. A propagação da espécie se dá, normalmente, via semente, mas esse processo é demorado, \\ pois a semente pode levar até 18 meses para germinar. A propagação vegetativa pode ser a solução para a produção de mudas. Este \\ trabalho avaliou o uso de AIB para a propagação vegetativa de $C$. edulis, utilizando diferentes tipos de estacas e concentrações \\ de AIB, em um delineamento experimental em blocos casualizados, seguindo o esquema fatorial 4 x 3 , sendo os fatores: 4 tipos \\ de estacas e 3 concentrações de AIB $\left(0,3.000\right.$ e $\left.6.000 \mathrm{mg} \mathrm{L}^{-1}\right)$. Ao final das avaliações, a maior porcentagem de emissão de \\ brotos ocorreu nas concentrações de $0 \mathrm{mg} \mathrm{L}^{-1}$ (testemunha) e $3.000 \mathrm{mg} \mathrm{L}^{-1}$ de AIB. A emissão de brotos foi maior em estacas \\ herbáceas sem folhas e semilenhosas. As maiores porcentagens de formação de calos foram obtidas na testemunha e em estacas \\ herbáceas com folhas inteiras e folhas pela metade. A emissão de raízes mostrou uma tendência maior nas estacas sem o uso \\ de AIB e na concentração de $6.000 \mathrm{mg} \mathrm{L}^{-1}$. A maior emissão de raízes ocorreu nas estacas herbáceas com folhas. No entanto, \\ a porcentagem de sucesso ainda é baixa, mas sugere a utilização de concentrações menores de AIB.
}

PALAVRAS CHAVE: Couepia edulis Prance, Propagação vegetativa, concentrações de hormônio.

\section{Rooting of cutia nut cuttings with indolbutiric acid}

\section{ABSTRACT}

The oily cutia nut (Couepia edulis Prance) is native to Amazonian uplands and most frequent in the State of Amazonas. The propagation of the species is usually by seed, but the process is long, as the seed may take 18 months to germinate. Vegetative propagation can be the solution for production of seedlings. This study evaluated the use of IBA in the vegetative propagation of C. edulis, using different types of cuttings and IBA concentrations, in an experimental design with randomized blocks, using a $4 \times 3$ factorial, with 4 types of cuttings and 3 IBA concentrations $\left(0,3,000\right.$ and $\left.6,000 \mathrm{mg} \mathrm{L}^{-1}\right)$. At the end of the evaluations, the best emission of shoots occurred in the concentrations of $0 \mathrm{mg} \mathrm{L}^{-1}$ and $3.000 \mathrm{mg} \mathrm{L}^{-1}$ of IBA. The emission of shoots was better in herbaceous cuttings without leaves and in semi-woody cuttings. The best callus formation occurred in the control and in the herbaceous cuttings with whole leaves and half leaves. The emission of roots was slightly better in the cuttings without the use of IBA and in the concentration of $6.000 \mathrm{mg} \mathrm{L}^{-1}$. The best emission of roots occurred in the herbaceous cuttings with leaves. The percentage of success was low, but suggests the use of smaller concentrations of IBA.

KEY WORDS: Couepia edulis Prance, Vegetative propagation, hormone concentrations

${ }^{1}$ Instituto Nacional de Pesquisas da Amazônia - INPA, caju@inpa.gov.br

2 Instituto Nacional de Pesquisas da Amazônia - INPA, kyuyama@inpa.gov.br 


\section{INTRODUÇÃO}

A espécie Couepia edulis Prance, conhecida vulgarmente como castanha-de-cutia, pertence a família Chrysobalanaceae, e é uma planta de origem amazônica que ocorre nas matas de terra firme, com precipitação média de $2500 \mathrm{~mm}$ anuais onde não há estação seca pronunciada. A espécie é endêmica da região central da Amazônia, entre Tefé e Coari no Amazonas (FAO, 1987). Porém, Higuchi et al. (1982), citados por Minetti e Sampaio (2000), afirmam que levantamentos realizados pelo INPA indicam sua ocorrência também nos rios Solimões, Trombetas, Ituí e em Atalaia do Norte.

O fruto é uma drupa elíptica, lisa e semelhante a uma noz, de 7 a $9 \mathrm{~cm}$ de comprimento e 4 a 5,5 cm de diâmetro; o pericarpo é duro, lenhoso e fibroso, de 8 a $10 \mathrm{~mm}$ de espessura (Cavalcante, 1996). O peso médio do fruto é de 82 gramas e o peso médio da amêndoa é de 15,5 gramas, o que representa $19 \%$ do peso do fruto (Le Cointe, 1934).

A planta floresce e frutifica entre fevereiro e março e o fruto leva cerca de 12 meses para completar a maturação (FAO, 1987). De acordo com Cavalcante (1996), os frutos estão maduros de novembro a maio.

O potencial econômico da espécie é a sua amêndoa, que possui $16,6 \%$ de proteína e cerca de $73 \%$ de óleo, normalmente utilizado para alimentação e na fabricação de sabão caseiro pelas populações tradicionais da região (Cavalcante, 1996; FAO, 1987). Pesce (1941) examinou mais de 120 espécies oleaginosas da Amazônia e sugeriu que a $C$. edulis é uma espécie promissora, notadamente, pelo seu potencial na produção de óleo.

A propagação da espécie é normalmente feita via semente, que apresenta germinação relativamente rápida e uniforme, quando se utilizam sementes recém extraídas dos frutos (FAO, 1987; Minetti e Sampaio, 2000). Porém, para que a germinação da semente seja rápida, tem de se fazer a retirada do pericarpo para facilitar a entrada da água até a amêndoa (Souza et al., 1996). Sem a remoção do pericarpo as sementes podem levar entre seis e dezoito meses para germinar.

$\mathrm{Na}$ fruticultura a propagação sexuada tem importância restrita (Fachinello et al., 2005), enquanto que a propagação assexuada é largamente utilizada na produção de mudas. Isso se deve à necessidade de garantir a manutenção das características varietais, que determinam o valor agronômico do material a ser propagado. Os autores destacam ainda que a estaquia é um dos principais métodos de propagação vegetativa utilizados na multiplicação de plantas frutíferas.

O uso de fitohormônios por meio de aplicação exógena proporciona maior porcentagem, velocidade, qualidade e uniformidade de enraizamento em muitas espécies (Hartmann et al., 1997). O ácido indolbutírico (AIB) tem sido usado para enraizamento de estacas de diversas espécies arbóreas (Berhe e Negash, 1998). O teor adequado de auxina exógena para estímulo do enraizamento, no entanto, depende da espécie e da concentração de auxina existente no tecido (Fachinello et al., 2005).

Este trabalho teve como objetivo avaliar o enraizamento de estacas de castanha-de-cutia, utilizando diferentes tipos de estacas e concentraçōes de Ácido Indolbutírico (AIB).

\section{MATERIAL E MÉTODOS}

O experimento foi realizado no Campus da Coordenação de Pesquisas em Ciências Agronômicas do Instituto Nacional de Pesquisas da Amazônia - INPA, Manaus, Amazonas, cujas coordenadas geográficas são: latitude de $02^{\circ} 08^{\prime} 07^{\prime \prime} \mathrm{S}$, longitude de 60 $01^{\prime} 38^{\prime \prime}$ W e altitude de 40 metros. O clima local é caracterizado como "Ami" na classificação de Köppen, com pluviosidade e temperatura média anual de $2458 \mathrm{~mm}$ e $25,6^{\circ} \mathrm{C}$, respectivamente, com estação seca de junho a outubro (Ribeiro, 1976).

As estacas de C. edulis foram coletadas em plantas cultivadas na Estação Experimental de Fruticultura Tropical do INPA, localizada na Rodovia BR 174, Km 42 em Manaus. As matrizes são procedentes dos municípios de Coari e Santo Antônio do Içá, no Estado do Amazonas. A retirada das estacas se deu a partir de ramos novos (do ano), localizados na parte mais próxima da base da planta, como forma de obter material com maior poder de enraizamento. Foram utilizadas estacas semilenhosas e herbáceas, com tamanho aproximado de 25 $\mathrm{cm}$ de comprimento e 5 a $8 \mathrm{~mm}$ de diâmetro, sendo que as estacas com folhas inteiras e meias folhas tinham três a cinco folhas. O material coletado foi acondicionado em caixas de polipropileno contendo água, para manutenção da umidade, até o preparo das estacas e a imersão na solução de AIB.

O delineamento experimental adotado foi blocos casualizados, com quatro repetiçôes, em esquema fatorial 4 x 3, sendo 4 tipos de estacas (estacas herbáceas com folhas inteiras, estacas herbáceas com meias folhas, estacas herbáceas sem folhas e estacas semilenhosas sem folhas) e 3 concentrações de AIB (0 - testemunha, 3.000 e $6.000 \mathrm{mg} \mathrm{L}^{-1}$ ). Cada parcela experimental foi composta de 10 estacas.

As estacas tiveram suas bases imersas na solução de AIB por cinco segundos. O plantio das estacas ocorreu imediatamente após a imersão na solução.

$\mathrm{O}$ experimento foi instalado na casa de vegetação, com sistema de nebulização intermitente e com cobertura plástica, inclusive nas laterais para manutenção da umidade. No canteiro, pó de serra curtido foi usado como substrato.

Os seguintes parâmetros foram avaliados mensalmente durante 6 meses: emissão de brotos (gema), formação de calos e emissão de raízes. Para efeito de análise estatística os resultados em porcentagem foram transformados em arc sen 
$\sqrt{ } \mathrm{x} / 100$ e as médias foram comparadas pelo teste de Tukey a 5\% de probabilidade (Gomes, 1987).

\section{RESULTADOS E DISCUSSÃO}

Houve efeito das diferentes concentrações de AIB aos 30 e 60 dias na emissão de brotos (Figura 1). A brotação atingiu o auge aos 60 dias, quando a testemunha diferiu das concentrações de $3.000 \mathrm{mg} \mathrm{L}^{-1}$ e $6.000 \mathrm{mg} \mathrm{L}^{-1}$ de AIB. A brotação, no entanto, foi diminuindo gradativamente até os 180 dias, ao mesmo tempo em que os brotos existentes secavam. Embora a aplicação de AIB implique, teoricamente, no favorecimento de brotação e enraizamento, estes dados sugerem que as reservas nutritivas contidas nas estacas teriam sido responsáveis pela maior predisposição para a emissão da brotação na parte aérea (Fachinello et al., 2005; Hartmann et al., 1997).

Leandro et al. (2007) encontraram respostas similares na mesma espécie $C$. edulis e com a mesma metodologia, porém com o Ácido Naftaleno Acético (ANA). Estes autores concluíram que houve maior emissão de brotação em estacas sem o uso de ANA, e que as concentrações usadas no experimento (200 e $2000 \mathrm{mg} \mathrm{L}^{-1}$ ) não induziram a formação de brotos.

A testemunha apresentou a maior formação de calos nas estacas com folhas inteiras e meias folhas (Figura 2). Este resultado está de acordo com Fachinello at al. (2005), quando dizem que muitas vezes a formação de calo é observada, na base da estaca, como resultado de um traumatismo durante o preparo da mesma. Entretanto, substâncias inibidoras do enraizamento contidas em plantas adultas poderiam ser a razão da não formação de calos (Hartmann et al., 1997). Sampaio (1987) destaca ainda que a rapidez na formação de calos muitas vezes determina o êxito do plantio de estacas

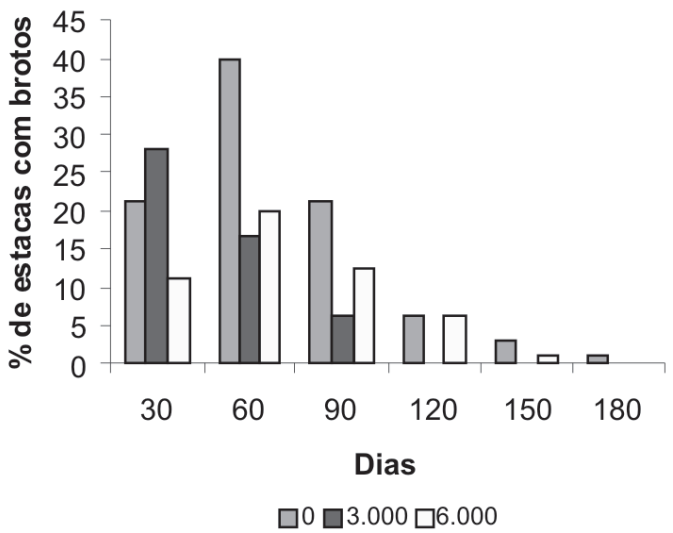

Figura 1 - Efeito de concentrações de AIB na emissão de brotos até 180 dias em estacas de castanha-de-cutia (Couepia edulis). Manaus - AM, 2005. em algumas espécies florestais, porém, nem sempre está relacionado com a formação de raízes, já que são processos fisiológicos independentes.

Aos 180 dias, os tratamentos sem utilização de AIB (testemunha) apresentaram tendência de maior porcentagem de enraizamento, seguidos dos tratamentos com concentração de $6.000 \mathrm{mg} \mathrm{L}^{-1}$ de AIB (Figura 3). Observamos ainda que, apesar de não ter efeito significativo entre as concentrações de AIB, a porcentagem de emissão de raízes aumentou com o tempo em todos os tratamentos. Estes eventos podem estar relacionados a fatores como condiçōes fisiológicas, potencial genético de enraizamento e balanço hormonal (Fachinello et al., 2005), pois a capacidade de uma estaca emitir raízes é função de fatores endógenos e das condiçōes ambientais proporcionadas ao enraizamento, e o teor adequado de auxina exógena depende da espécie e da concentração de auxina existente no tecido.

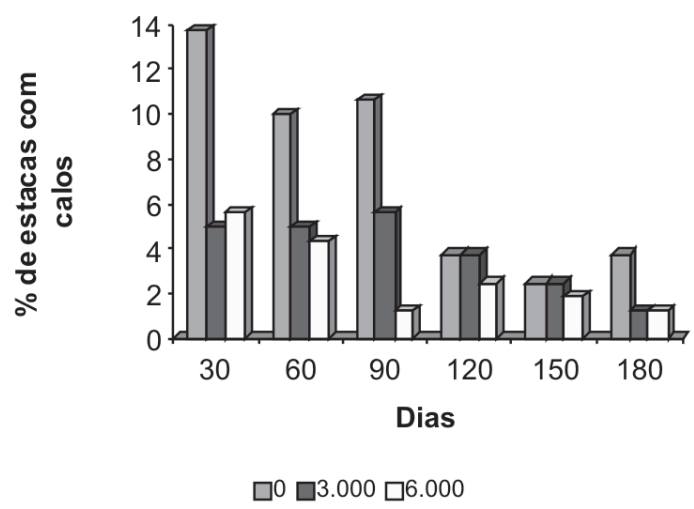

Figura 2 - Efeito de concentrações de AIB na formação de calos até 180 dias em estacas de castanha-de-cutia (Couepia edulis). Manaus - AM, 2005.

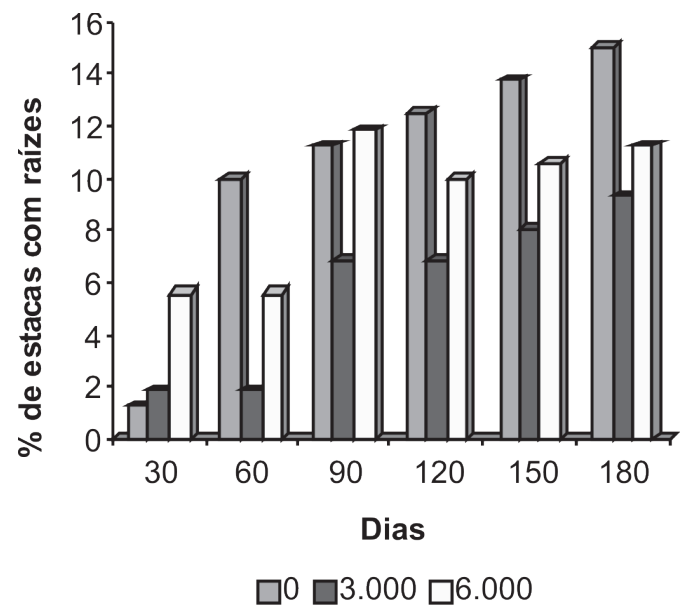

Figura 3 - Efeito das concentrações de AIB na emissão de raízes até 180 dias em estacas de castanha-de-cutia (Couepia edulis). Manaus - AM, 2005. 
Neste contexto, Scarpare Filho et al. (1999), ainda que trabalhando com espécie diferente, verificaram que não houve enraizamento de estacas sem a utilização de fitohormônio. Ao contrário, Santana (1998) verificou o enraizamento de estacas de pau-rosa (Aniba rosaeodora) sem tratamento hormonal, atribuindo este fato à idade das estacas.

Aos 180 dias, as estacas herbáceas com folhas (inteiras e meias folhas) apresentaram maiores emissōes de raízes, diferindo das estacas herbáceas e semilenhosas sem folhas (Figura 4). O resultado está de acordo com Fachinello et al. (2005), quando afirmam que o uso de estacas da porção basal geralmente proporciona melhores resultados no enraizamento. Isso pode ser devido ao acúmulo de substâncias de reserva e um menor teor de nitrogênio (resultando numa relação $\mathrm{C} / \mathrm{N}$ mais favorável) e à presença de iniciais de raízes pré-formadas nessa região. Por outro lado, Hartmann et al. (1997) enfatizam que a presença de folhas nas estacas exerce uma forte ação estimulante sobre a iniciação das raízes, não apenas como fonte de carboidratos, mas provavelmente devido ao fato das folhas e gemas serem poderosos produtores de auxinas. Nas folhas ocorrem reações de síntese de produtos necessários para o processo morfogenético de formação de raízes adventícias em tecidos já diferenciados, como reguladores de crescimento e co-fatores de enraizamento (Hartmann et al., 1997).

Todavia, Fachinello et al. (2005) garantem que o aumento da concentração de auxina exógena, aplicada em estacas, provoca efeito estimulador de raízes até um valor máximo, a partir do qual qualquer acréscimo de auxinas tem efeito inibitório. Estes fatores podem ter sido determinantes para os resultados obtidos com os diferentes tipos de estacas utilizados neste trabalho.

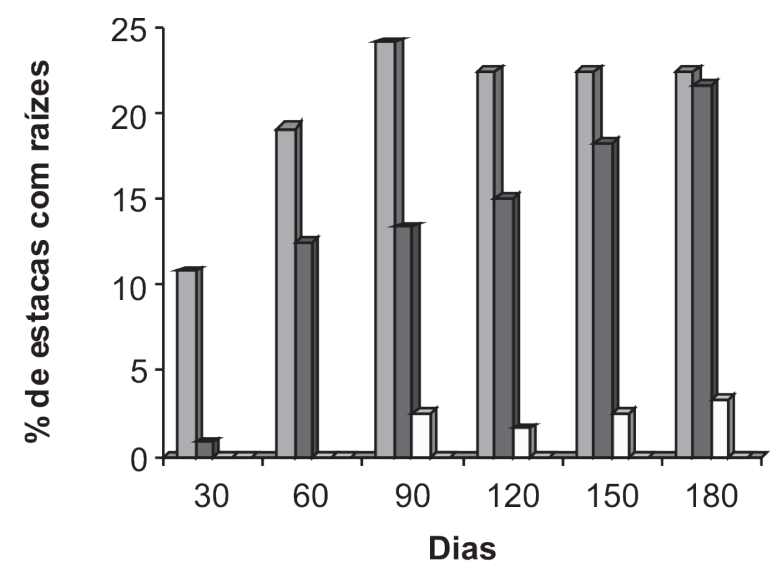

Folhas inteiras $\square$ Meias folhas $\square$ Herb s/folhas $\square$ Semilenhosas

Figura 4 - Efeito dos tipos de estacas na emissão de raízes até 180 dias, em estacas de castanha-de-cutia (Couepia edulis). Manaus - AM, 2005.

\section{CONCLUSÕES}

As estacas herbáceas com folhas inteiras e folhas pela metade apresentaram maiores percentuais de enraizamento sem o uso de AIB. Portanto, é possível propagar vegetativamente a castanha-de-cutia pelo método da estaquia, sem aplicação exógena de fitohormônios, quando se usam estacas herbáceas com folhas (inteiras ou folhas pela metade). Todavia, sugerese o aprofundamento das pesquisas, testando a utilização de concentrações menores de AIB e analisado a sobrevivência das estacas, para mostrar a viabilidade do processo.

\section{BIBLIOGRAFIA CITADA}

Berhe, D.; Negash, L. 1998. Assexual propagation of Juniperus procera Hoechst. ex Endl. from Etiopia: a contribution to the conservation of African pencil cedar. Forest Ecology and Management, 112(1-2): 179-190.

Cavalcante, P.B. 1996. Frutas comestíveis da Amazônia. 6a ed. CNPq e Museu Paraense Emílio Goeldi (Coleção Adolpho Ducke), Belém. 279pp.

Fachinello, J.C.; Hoffmann, A.; Nachtigal, J.C. (Eds). 2005. Propagação de plantas frutiferas. Embrapa Informações Tecnológicas, Brasília, DF. 221pp.

FAO. 1987. Especies florestales productoras de frutas y otros alimentos. 3. Ejemplos de América Latina, 44/3. FAO, Roma. 241pp.

Gomes, F.P. 1987. Curso de estatística experimental. 12a ed. Piracicaba, Nobel. 467 p.

Hartmann, H.T.; Kester, D.E.; Davies Jr., F.T. 1997. Plant propagation; principles and practices. 6 ed. New Jersey: Prentice Hall. 770pp.

Leandro, R.C.; Murta, G.C.; Yuyama, K. 2007. Produção de mudas de castanha-de-cutia (Couepia edulis Prance) utilizando ácido naftaleno acético (ANA). Revista Brasileira de Biociências, 5(1): 87-89.

Le Cointe, P. 1934. Arvores e plantas úteis (indigenas e aclimatadas). Série: A Amazônia Brasileira, no 3. Livraria Clássica, Belém.

Minetti, L.; Sampaio, P.T.B. 2000. Castanha-de-cutia (Couepia edulis). In: Clay, J.W.; Sampaio, P.T.B.; Clement, C.R. (Eds). Biodiversidade Amazônica, Exemplos e Estratégias de Utilização. SEBRAE e INPA, Manaus. p.110-117.

Pesce, C. 1941. Oleaginosas da Amazônia. Oficinas Gráficas da Revista Veterinária, Belém.

Ribeiro, M.N.G. 1976. Aspectos climatológicos de Manaus. Acta Amazonica, 6(2): 229-233.

Sampaio, P.T.B. 1987. Propagação vegetativa do pau-rosa (Aniba rosaeodora Ducke) pelo método de estaquia. Dissertação de Mestrado, Instituto Nacional de Pesquisas da Amazônia/ Fundação Universidade Federal do Amazonas, Manaus, Amazonas. p.36-37

Santana, S.C. 1998. Propagação vegetativa, por meio de estaquia e enxertia com diferentes porta-enxertos de Myrtaceae, para camu-camu (Myrciaria dubia (H.B.K) McVaugh). Dissertação de Mestrado, Instituto Nacional de Pesquisas da Amazônia/ 


\section{ACTA}

Fundação Universidade Federal do Amazonas, Manaus, Amazonas. 89pp.

Scarpare Filho, J.A.; Tessarioli Neto, J.; Costa Júnior, W.H.; Kluge, R.A. 1999. Efeito do ácido indolbutírico no enraizamento de estacas herbáceas de Jabuticabeira 'Sabará' (Myrciaria jabuticaba (Vell.) Berg.) em condiçôes de nebulização. Revista Brasileira de Fruticultura, 21(2): 146-149.

Souza, A.G.C.; Sousa, N.R.; Silva, S.E.L.; Nunes, C.D.M.; Canto, A.C.; Cruz, L.A.A. 1996. Fruteiras da Amazônia. Embrapa-SPI, Brasília. 204 pp.

Recebido em 09/10/2007

Aceito em 27/09/2008 
